\title{
Acquiring Conceptual Knowledge about How Systems Behave
}

\author{
Jochem Liem ${ }^{1}$, Bert Bredeweg ${ }^{1, *}$, Floris Linnebank ${ }^{1}$, René Bühling ${ }^{2}$, \\ Michael Wißner ${ }^{2}$, Jorge Gracia del Río ${ }^{3}$, Wouter Beek ${ }^{1}$, and Asunción Gómez Pérez ${ }^{3}$ \\ ${ }^{1}$ University of Amsterdam, Informatics Institute, Amsterdam. Netherlands \\ B. Bredewegeuva.nl \\ ${ }^{2}$ University of Augsburg, Multimedia Concepts and Applications, Augsburg, Germany \\ ${ }^{3}$ Universidad Politécnica de Madrid, Ontology Engineering Group, Madrid, Spain
}

There is a need for software that supports learners in actively dealing with theoretical concepts by having them create models and perform concept prediction and explanation (e.g. $[3,4,5]$ ). DynaLearn seeks to address this by developing a domain independent Interactive Learning Environment (ILE) based on Qualitative Reasoning (QR) [1]. The $Q R$ vocabulary fits the nature of conceptual knowledge, and the explicit representation of these notions in the software provides the handles to support an automated communicative interaction that actually discusses and provides feedback at the conceptual level.

DynaLearn seeks to provide an instrument for studying the characteristics under which learners develop conceptual knowledge, particularly for ill-defined domains. The DynaLearn ILE offers a suite of technical advances for educational research. The following features can be manipulated (see [2] for design specifications). (i) Uselevels adapt the interface and tool interaction to tailor for groups of a specific age or experience. (ii) Different types of knowledge-based feedback, such as recommending terminology, model quality feedback, and suggestions for model improvements. (iii) Learner interaction through virtual characters with roles such as student, peer, teacher, critic and quizmaster. More specifically the following features will be demonstrated during the interactive event: $(a)$ Workbench and its multiple use-levels, $(b)$ Basic help, (c) Grounding, (d) Teachable agent, and (e) Quiz. The audience will be allowed to work with the software as if they were students.

\section{References}

1. Bredeweg, B., Linnebank, F.. Bouwer, A., Liem, J.: Garp3 - Workbench for Qualitative Modelling and Simulation. Ecological Informatics 4(5-6). 263-281 (2009)

2. André, E.. Bee, N., Bühling, R.. Gómez-Pérez. J.M.. Häring, M., Liem. J., Linnebank. F.: Technical design and architecture. In: Bredeweg, B. (ed.) DynaLearn. EC FP7 STREP project 231526, Deliverable D2.1 (2009)

3. Hucke, L., Fischer, H.E.: The link of theory and practice in traditional and in computerbased university laboratory experiments. In: Psillos, D.. Niedderer, H. (eds.) Teaching and learning in the science laboratory, pp. 205-218. Kluwer, Dordrecht (2002)

4. Otero, V., Johnson, A., Goldberg. F.: How Does the Computer Facilitate the Development of Physics Knowledge Among Prospective Elementary Teachers? Journal of Education 181(2), 57-89 (1999)

5. Osbome, J., Simon. S., Collins. S.: Attitudes towards science: a review of the literature and its implications. Int. Journal of Science Education 25(9), 1049-1079 (2003) 